\title{
Evolution Procedure of Multiple Rock Cracks under Seepage Pressure
}

\author{
Taoying Liu, ${ }^{1}$ Ping Cao, ${ }^{1}$ and Hang Lin ${ }^{1,2}$ \\ ${ }^{1}$ School of Resources \& Safety Engineering, Central South University, Changsha, Hunan 410083, China \\ ${ }^{2}$ State Key Laboratory of Coal Resources and Safe Mining, China University of Mining and Technology, Xuzhou, Jiangsu 221116, China \\ Correspondence should be addressed to Hang Lin; linhangabc@126.com
}

Received 20 January 2013; Revised 23 April 2013; Accepted 1 May 2013

Academic Editor: Gianluca Ranzi

Copyright (c) 2013 Taoying Liu et al. This is an open access article distributed under the Creative Commons Attribution License, which permits unrestricted use, distribution, and reproduction in any medium, provided the original work is properly cited.

\begin{abstract}
In practical geotechnical engineering, most of rock masses with multiple cracks exist in water environment. Under such circumstance, these adjacent cracks could interact with each other. Moreover, the seepage pressure, produced by the high water pressure, can change cracks' status and have an impact on the stress state of fragile rocks. According to the theory of fracture mechanics, this paper discusses the law of crack initiation and the evolution law of stress intensity factor at the tip of a wing crack caused by compression-shear stress and seepage pressure. Subsequently, considering the interaction of the wing cracks and the additional stress caused by rock bridge damage, this paper proposes the intensity factor evolution equation under the combined action of compression-shear stress and seepage pressure. In addition, this paper analyzes the propagation of cracks under different seepage pressure which reveals that the existence of seepage pressure facilitates the wing crack's growth. The result indicates that the high seepage pressure converts wing crack growth from stable form to unstable form. Meanwhile, based on the criterion and mechanism for crack initiation and propagation, this paper puts forward the mechanical model for different fracture transfixion failure modes of the crag bridge under the combined action of seepage pressure and compression-shear stress. At the last part, this paper, through investigating the flexibility tensor of the rock mass's initial damage and its damage evolution in terms of jointed rock mass's damage mechanics, deduces the damage evolution equation for the rock mass with multiple cracks under the combined action of compression-shear stress and seepage pressure. The achievement of this investigation provides a reliable theoretical principle for quantitative research of the fractured rock mass failure under seepage pressure.
\end{abstract}

\section{Introduction}

In recent years, rock mechanics is supposed to consider the most striking feature of rock masses that their blocky structures are caused by the discontinuity surfaces such as joints, cracks, and faults. As frictional force is overcome by shear stress induced by far-field stresses near the crack surface, the crack surface is inclined to slide over each other, which induces stress concentration on tip of crack and leads to the initiation and splitting propagation of the wing crack at last [1-3]. Worse, the existence of seepage pressure could reinforce the trend of the microfracture and fault degradation to fractured rock masses. With the development of rock mechanics engineering, increasing number of situations is involved in seepage pressure which results in numerous engineering accidents around the world $[4,5]$. Hence, researches on rock mechanics referring to seepage pressure are gradually becoming a hot spot in the area of geotechnical engineering. A vast number of scholars have made great effort in developing crack propagation theories [6-8] or developing techniques to calculate the stress intensity factors of crack tips [9-12], or studying the relationship between microdamage development and macrodeformation of rock under uniaxial compression [13-15]. Nevertheless, the former studies mainly focus on mechanical mechanism of special single crack rather than the effect of seepage pressure. Besides, there are few reasonable models for evolution laws of stress intensity factor for the branch crack tip in the multicrack rock mass, as well 


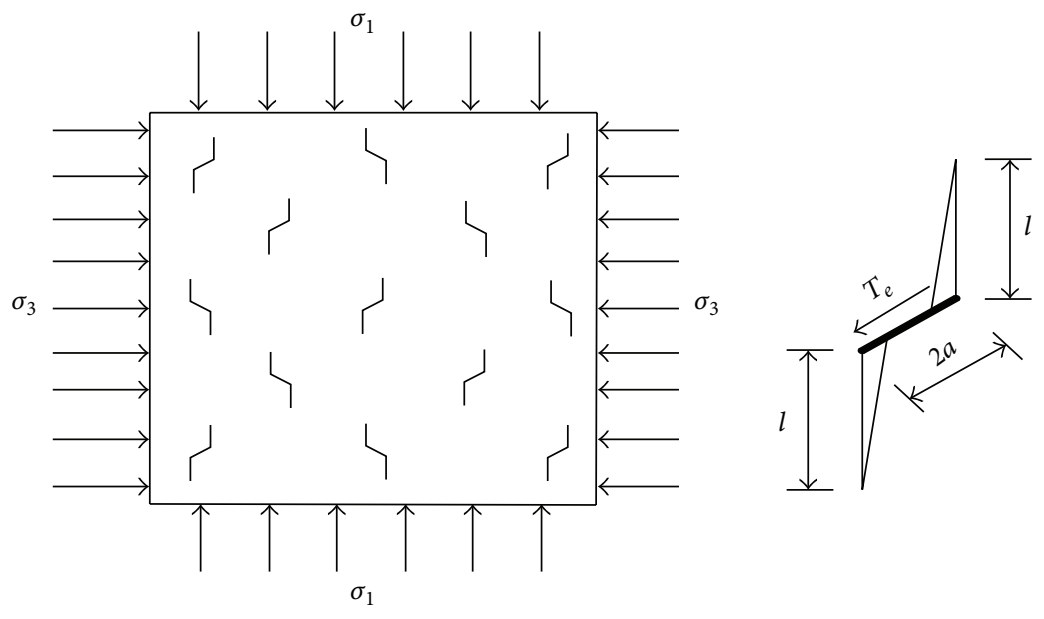

FIGURE 1: Sketch of wing cracks seeding and propagation.

as studies of the damage and fracture evolution mechanism of the fractured rock mass with multiple cracks under seepage pressure.

As for the multicrack rock mass, the mechanical state on the crack surface could be changed by the action of seepage pressure. As the branch crack expands, the interaction of cracks leads to the continuous degradation of the macroscopic mechanical properties of the rock mass [8]. The interaction theory of multiple cracks in rock masses is a key factor in the analysis of microdamage mechanism. Therefore, based on previous studies and the rock fracture mechanics criterion, this paper proposes the mechanical model of the multicrack rock mass under the action of seepage pressure and investigates traits of gradual fracture and damage evolution of the multicrack rock under seepage pressure on the basis of exploring the law of the compression-shear crack initiation, branch crack growth, and rock bridge connection. Then, this paper applies the self-consistent theory to setting up the constitutive and damage evolution equation for the multicrack rock mass under seepage pressure.

\section{Analysis of Compression-Shear Multicrack Damage Fracture Models}

2.1. Crack Initiation. The underground rock usually exists in a compression stress state, and a lot of testing results and theoretical calculation prove that cracks expand approximately in the direction perpendicular to the maximum principal stress $[16,17]$ as shown in Figure 1.

Firstly, this paper assumes that the rock mass is categorized as crisp flexible, meeting the theory of linear elastic fracture mechanics, and the seepage pressure is equal in every directions along the crack. The fractured rock mass is under the remote field stress $\sigma_{1}$ and $\sigma_{3}$, where $\sigma_{1}$ is the maximum principal stress, $\sigma_{1} \geq \sigma_{3}$. The angle between the crack and vertical stress $\sigma_{1}$ is $\psi$, and there is a seepage pressure $p$ in the crack. The normal stress on the crack surface is compressive stress. The shear stress forces the crack to slide which generates a friction $\mu \sigma_{n e}+C$ owing to the part closure of the crack, where $\mu$ is the friction coefficient on the crack surface and $C$ is the cohesion on the crack surface. Meanwhile, introducing the coefficient $\beta$ which presents the ratio of the connected area to the total area, the seepage pressure contributes $\beta p$ to the surface. Therefore, the effective shear driving force $\tau_{\text {eff }}$ and effective normal stress $\sigma_{n e}$ appear in following formulas [18] (here the compressive stress is positive):

$$
\begin{gathered}
\sigma_{n e}=\sigma_{n}-\beta p=\left(1-C_{n}\right)\left(\sigma_{1} \sin ^{2} \psi+\sigma_{3} \cos ^{2} \psi\right)-\beta p, \\
\tau_{\text {eff }}=\left(1-C_{v}\right) \frac{\sigma_{1}-\sigma_{3}}{2} \sin ^{2} \psi-\mu \sigma_{n e}-C, \\
C_{n}=\frac{\pi a}{\pi a+\left(E_{0} /\left(1-v_{0}^{2}\right) K_{n}\right)}, \\
C_{v}=\frac{\pi a}{\pi a+\left(E_{0} /\left(1-v_{0}^{2}\right) K_{s}\right)}
\end{gathered}
$$

where $C_{n}$ and $C_{v}$ are the compression transmitting factor and shearing transmitting factor, respectively, which are resulted from the part closure of the crack.

According to the maximum circumferential stress criterion, the initial crack extends along the direction of the maximum normal stress. Thus, the cracking angle $\theta_{3}$ can be obtained $\left(\theta_{3}=70.5^{\circ}\right)$ [19]. Then, the stress intensity factor at the wing crack initiation can be concluded as [20]

$$
K_{I}=\frac{2}{\sqrt{3}} \tau_{\text {eff }} \sqrt{\pi a}
$$

Making $K_{I}=K_{I C}$ in (2), $K_{I C}$ is the fracture toughness, the biggest crack stress intensity factor. It is easy to get the ultimate strength $\sigma_{11}$ of the fracture rock under seepage pressure

$$
\begin{gathered}
\sigma_{11}=\frac{\sqrt{3} K_{I C} / \sqrt{\pi a}+2 C-2 \mu \beta p+B \sigma_{3}}{A}, \\
A=-\mu\left(1-C_{n}\right)\left(1-\cos ^{2} \psi\right)+\left(1-C_{v}\right) \sin ^{2} \psi, \\
B=\mu\left(1-C_{n}\right)\left(1+\cos ^{2} \psi\right)+\left(1-C_{v}\right) \sin ^{2} \psi .
\end{gathered}
$$




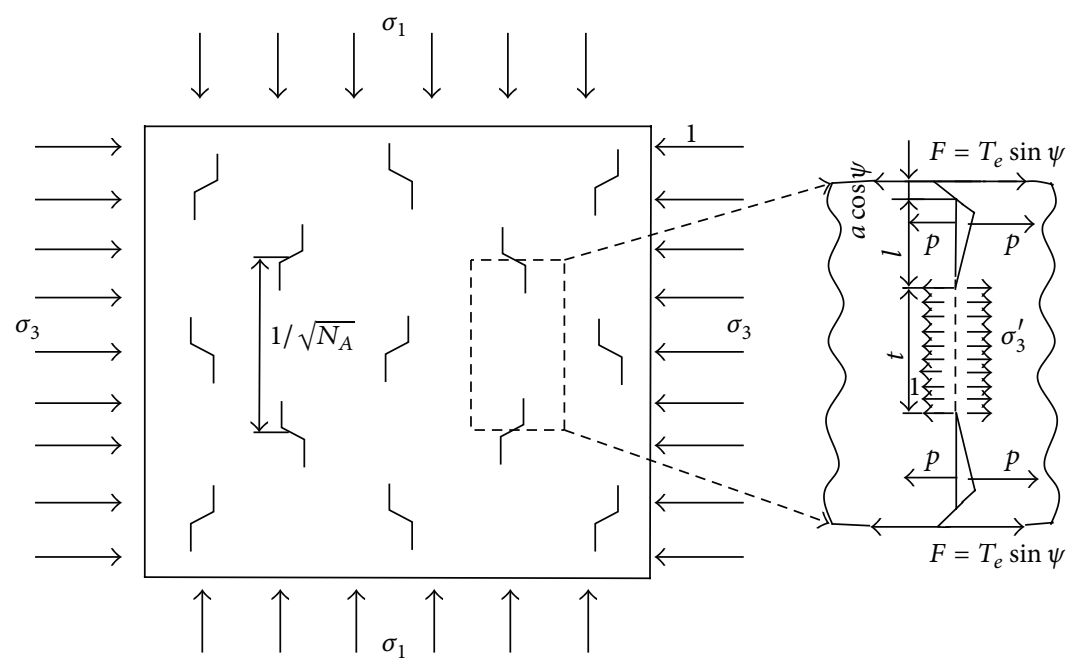

FIGURE 2: Schematic drawing of multiple interacting cracks. $F$ is the horizontal stress in the crack. $\sigma_{3}^{\prime}$ is the horizontal stress in the rock bridge, and $t$ is the length of the rock bridge.

From (3a), it is clear to see that the ultimate strength $\sigma_{11}$ decreases linearly with the increase of the seepage pressure $p$.

As for multicrack rock masses, when at the initial stage of crack expansion or the crack space is relatively large, it can be treated as the wing crack propagation of a single crack. Under such circumstance, the stress intensity factor $K_{I}$ at the crack tip could be defined through the revised wing crack calculation model [21]. Considering the additional seepage pressure in the crack, the stress intensity factor $K_{I}$ consists of the stress intensity factor produced by the effective shear driving force $T_{e}$ and the remote field stress $\sigma_{1}$ and $\sigma_{3}$, and it can be shown as in (4)

$$
\begin{aligned}
K_{I}= & 3 \tau_{n e} \sqrt{\frac{a l_{t y}}{\pi}} \sin ^{-1}\left(\frac{1}{l_{t y}}\right) \sin \theta \cos \frac{\theta}{2} \\
& -\frac{1}{2}\left[\left(\sigma_{1}+\sigma_{3}\right)+\left(\sigma_{1}-\sigma_{3}\right) \cos ^{2}(\theta+\beta)\right] \sqrt{\pi l}+p \sqrt{\pi l},
\end{aligned}
$$

where $l_{t y}$ is the impact factor which is the function of the wing crack length $l$, wing crack azimuth $\theta$, and main crack length $a$, as shown in (5)

$$
l_{t y}=\left[1+\frac{9 l}{4 a} \cos ^{2}\left(\frac{\theta}{2}\right)\right]\left(1-e^{-l / a}\right)+0.667 \sec ^{2}\left(\frac{\theta}{2}\right) e^{-l / a} \text {. }
$$

The wing crack extends approximately in the direction perpendicular to the maximum principal stress until $K_{I}=$ $K_{I C}$, and then the wing crack propagation length $l$ under the combined action of compression-shear stress and seepage pressure can be calculated as shown in (6)

$$
l=\frac{6 \tau_{n e} \sqrt{\left(a l_{t y} / \pi\right)} \sin ^{-1}\left(1 / l_{t y}\right) \sin \theta \cos (\theta / 2)-2 K_{I C}}{\left[\left(\sigma_{1}+\sigma_{3}\right)+\left(\sigma_{1}-\sigma_{3}\right) \cos ^{2}(\theta+\beta)-2 p\right] \sqrt{\pi}} .
$$

2.2. The Multicrack Interaction Models. As the crack expands or when the crack space is relatively small, the interaction between cracks leads to a damaged connection and unstable break of the rock bridge [22]. The rock bridge interaction mechanical model of the multicrack rock mass with the wing crack expansion is shown in Figure 2.

Assuming that the number of the compression-shear cracks per unit area is $N_{A}$, the length between main crack centers and the rock bridge lengths between wing cracks, respectively, are presented as follows:

$$
\begin{gathered}
S=\frac{1}{\sqrt{N_{A}}}, \\
T=S-2(l+a \cos \psi) .
\end{gathered}
$$

In Figure $2, F=T_{e} \sin \psi$ is balanced by the tensile stress $\sigma_{3}^{\prime}$ in the rock bridge together with seepage pressure $p$ in the wing crack:

$$
\sigma_{3}^{\prime}=\frac{T_{e} \sin \psi+2 p l}{S-2(l+a \cos \psi)}
$$

where $T_{e}=2 a \tau_{n e}$.

Acting on the wing crack, $\sigma_{3}^{\prime}$ produces an additional intensity factor at the crack tip [23]:

$$
K_{I}^{\prime}=-\sigma_{3}^{\prime} \sqrt{\pi l}=\frac{a\left(\sigma_{1}-\sigma_{3}\right) \sin ^{2} \psi \sin \psi+2 p l}{N_{A}^{-1 / 2}-2(l+a \cos \psi)} \sqrt{\pi l} .
$$


Considering the damage to the rock bridge caused by the wing crack interaction, the stress intensity factor at the wing crack tip is composed of (4) and (9) as follows:

$$
\begin{aligned}
K_{I}= & K_{I}+K_{I}^{\prime}=3 \tau_{n e} \sqrt{\frac{a l_{t y}}{\pi}} \sin ^{-1}\left(\frac{1}{l_{t y}}\right) \sin \theta \cos \frac{\theta}{2} \\
& -\frac{1}{2}\left[\left(\sigma_{1}+\sigma_{3}\right)+\left(\sigma_{1}-\sigma_{3}\right) \cos ^{2}(\theta+\beta)\right] \sqrt{\pi l} \\
& +p \sqrt{\pi l}+\frac{a\left(\sigma_{1}-\sigma_{3}\right) \sin ^{2} \psi \sin \psi+2 p l}{N_{A}^{-1 / 2}-2(l+a \cos \psi)} \sqrt{\pi l} .
\end{aligned}
$$

From (10), it is clear to see that the interaction of multiple wing cracks in rock bridge damage makes the stress intensity factor at the crack tip larger than that at a single wing crack.

The process of rock fracture is the one of the increasing damage and inherent fracture in rock and is the coupling damage result of the microdamage and macrodamage. There are many ways to define the damage variable, such as the cracks quantity crack length, crack area, and crack density. Here, the cracks quantity is adopted to define $D_{0}$ for the initial damage of the rock mass and $D$ for the damage when the wing crack expands to $l$ :

$$
\begin{gathered}
D_{0}=\pi(a \cos \psi)^{2} N_{A}, \\
D=\pi(l+a \cos \psi)^{2} N_{A} .
\end{gathered}
$$

Substituting (11) into (8), the fellow equation can be easily obtained

$$
\sigma_{3}^{\prime}=-\frac{\left(\tau_{n e} \tan \psi+2 p l\right)\left(D_{0} / \pi\right)^{1 / 2}}{a\left(1-2(D / \pi)^{1 / 2}\right)}
$$

Combining (10), (11), and (12), the relation curves between the damage variables $D$ and dimensionless stress intensity factor $\left(K_{I} / \sigma_{1} \sqrt{\pi a}\right)$ at the wing crack tip with different crack density are shown in Figure 3.

The graph reveals that with the increase of the damage variables, the dimensionless stress intensity factor $K_{I} / \sigma_{1} \sqrt{\pi a}$ at the crack tip under seepage pressure decreases at the very beginning but rises gradually when the equivalent crack length is $0.5(l / a)$. The graph also illustrates that the sparser of the cracks are, the higher of the stress intensity at the wing crack will be when the rock bridge is connected. During the wing crack expansion process, the damage variable $D$ varies from $D_{0}$ to 1 . When $D=1$ and the wing crack stress intensity factor $K_{I} \geqslant K_{I C}$ at the crack tip, the wing crack connects, the rock bridge cracks, and the rock mass loses bearing capacity.

Figure 4 shows the relationship between the stress intensity factor at the crack tip and the equivalent crack propagation length under different seepage pressure. It can be concluded that when the seepage pressure is relatively low $(p=0 \mathrm{MPa})$, the wing crack expands stably

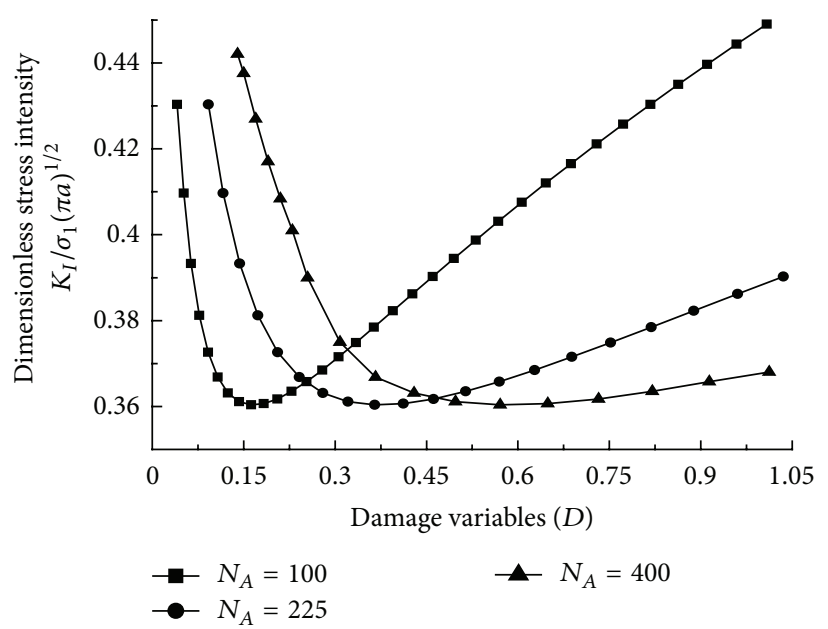

FIgURE 3: The relationship between damage variables and intensity factor at the crack tip of the branch stress.

$\left(\partial K_{I} / \partial L<0\right)$. While when the seepage pressure is relatively high $(p=15 \mathrm{MPa})$, the wing crack tends to expand unstably. Besides, there is the expansion stage that $\partial K_{I} / \partial L>0$ under such condition and the growth rate of wing crack stress intensity factor becomes greater with the increase of seepage pressure $p$. It indicates that under high seepage pressure, the compressive-shear rock crack expands at a high speed as long as it cracks, namely, and the high seepage pressure contributes to unstable expansion.

\section{Wing Crack Connection Model and Damage Criteria}

As the branch crack expands, the interaction of the crack results in the continuous degradation of the macroscopic mechanical properties of the rock mass. The wing crack initiation from microcracks to the completely damage of the rock mass is a process of evolution and accumulation of the rock mass damage, as well as a process of the fracture of the connection between cracks [24]. It has been proved by many experimental researches that the gradual damage process of the cracks generally has two forms $[25,26]$ : (1) the rock bridge axial transfixion failure and (2) the tension-shear compound failure. According to the branch crack propagation evolution mechanism, this paper studies the gradual damage features of those damage models.

3.1. The Axial Transfixion Failure. Whenever the wing crack extends stably or unstably, the tension wing crack connects the main crack in another row, as shown in Figure 5. When the wing crack reaches the critical length $l_{1 c}=D / \sin \psi$, $L_{1 C}=l_{1 c} / a$, the rock bridge starts to damage in the form of axial transfixion failure. Taking the stress intensity at the crack tip as the criterion when the wing crack reaches the 
critical length $l_{1 c}=D / \sin \psi$, this paper establishes the failure criteria:

$$
\begin{aligned}
K_{I}= & 3 \tau_{n e} \sqrt{\frac{a l_{t y}}{\pi}} \sin ^{-1}\left(\frac{1}{l_{t y}}\right) \sin \theta \cos \frac{\theta}{2} \\
& -\frac{1}{2}\left[\left(\sigma_{1}+\sigma_{3}\right)+\left(\sigma_{1}-\sigma_{3}\right) \cos ^{2}(\theta+\beta)\right] \sqrt{\pi l_{1 c}} \\
& +p \sqrt{\pi l_{1 c}}+\frac{a\left(\sigma_{1}-\sigma_{3}\right) \sin ^{2} \psi \sin \psi+2 p l_{1 c}}{N_{A}^{-1 / 2}-2\left(l_{1 c}+a \cos \psi\right)} \sqrt{\pi l_{1 c}} .
\end{aligned}
$$

When $K_{I}\left(L_{1 C}\right) \geq K_{I C}$, axial transfixion failure occurs in the rock bridge.

3.2. The Tension-Shear Compound Failure. With the expansion of wing cracks under seepage pressure, the cut-resistant capacity of the rock bridge is increasingly weakened. When the wing crack expands to a certain degree; the rock bridge at the crack tip between adjacent wing cracks is cut off by the shear stress, consequently, the crack is connected in the shear direction [27]. The mechanical analyzing diagram for the element of the rock bridge composite failure is shown in Figure 6, where $A B$ is $1 / 2$ the length of the bottom crack, $E F$ is $1 / 2$ the length of the upper crack, $C D$ is the rock bridge, $B C$ and $E D$ are the wing cracks produced by effective shear driving force of the main crack $A B$ and $E F, \theta$ is the angle between rock bridge and the maximum principal stress, and $\sigma_{C D}$ and $\tau_{C D}$ are the normal stress and shear stress acting on the rock bridge, respectively.

According to the element shown in Figure 6 and the principle of mechanics balance, it could be deduced as follows:

$$
\begin{gathered}
\sum F_{x}=0, \quad \sum F_{y}=0, \\
2 r_{3} \sigma_{3}-2 a\left(\tau_{n e} \sin \psi+\sigma_{n e} \cos \psi\right) \\
-2 r_{2}\left(\tau_{C D} \sin \theta+\sigma_{n}^{C D} \cos \theta\right)-2 p l=0, \\
2 r_{1} \sigma_{1}+2 a\left(\tau_{n e} \cos \psi-\sigma_{n e} \sin \psi\right) \\
+2 r_{2}\left(\tau_{C D} \cos \theta-\sigma_{n}^{C D} \sin \theta\right)=0,
\end{gathered}
$$

where

$$
\begin{gathered}
r_{1}=a \sin \psi+\frac{1}{2} \sqrt{d^{2}+h^{2}} \sin \theta, \\
r_{2}=\frac{\sqrt{d^{2}+h^{2}} \cos \theta-2 l}{2 \cos \theta}, \\
r_{3}=a \cos \psi+\frac{1}{2} \sqrt{d^{2}+h^{2}} \cos \theta, \\
\theta=\psi-\arctan \frac{d}{h}
\end{gathered}
$$

Then, the following equation can be obtained

$$
\begin{gathered}
\tau_{C D}=\frac{2 A_{1} \tan \theta-2 B_{1}}{\left(\sqrt{d^{2}+h^{2}} \cos \theta-2 l\right)\left(1+\tan ^{2} \theta\right)}, \\
\sigma_{C D}=\frac{2 A_{1}+2 B_{1} \tan \theta}{\left(\sqrt{d^{2}+h^{2}} \cos \theta-2 l\right)\left(1+\tan ^{2} \theta\right)}, \\
A_{1}=r_{3} \sigma_{3}-a\left(\tau_{n e} \sin \psi+\sigma_{n e} \cos \psi\right)-p l, \\
B_{1}=r_{1} \sigma_{1}+a\left(\tau_{n e} \cos \psi-\sigma_{n e} \sin \psi\right) .
\end{gathered}
$$

Assuming that the rock bridge shear damage follows the Mohr-Coulomb strength criterion, conditions for the damage are

$$
\tau_{C D}-c-\sigma_{C D} \tan \varphi \geqslant 0 .
$$

Substituting (16) into (18), the fellow equation can be easily obtained as follows:

$$
\begin{gathered}
\left(\frac{1}{2} \sqrt{d^{2}+h^{2}} \cos \theta-l\right) c \tan ^{2} \theta+\left(B_{1} \tan \varphi-A_{1}\right) \tan \theta \\
+A_{1} \tan \varphi+B+\frac{1}{2} c \sqrt{d^{2}+h^{2}} \cos \theta-c l \leqslant 0
\end{gathered}
$$

When angle $\theta$ meets the rock bridge shear failure condition and the wing crack propagation length reaches critical value $l_{2 c}$, the angle $\theta$ between the rock bridge and $\sigma_{1}$ also reaches their critical value, and then

$$
\theta_{c}=\arctan \frac{A_{1}-B_{1} \tan \varphi+\sqrt{\Delta}}{\left(\sqrt{d^{2}+h^{2}} \cos \theta-2 l_{2 c}\right) c} .
$$

As the geometric relations show in Figure 6, it is easy to see that

$$
\tan \theta_{c}=\frac{\sqrt{d^{2}+h^{2}} \sin \theta}{\left(\sqrt{d^{2}+h^{2}} \cos \theta-2 l_{2 c}\right)} .
$$

Combined (20) and (21), the critical length of the wing crack can be defined as:

$$
l_{2 c}=\frac{A_{2}-\sqrt{A_{2}^{2}-4(c+p \tan \varphi) B_{2}}}{2(c+p \tan \varphi)},
$$

where

$$
\begin{aligned}
A_{2}= & r_{3} \sigma_{3} \tan \varphi-a\left(\tau_{n e} \sin \psi+\sigma_{n e} \cos \psi\right) \tan \varphi+B_{1} \\
& +\frac{1}{2} \sqrt{d^{2}+h^{2}}[(2 c-p \tan \varphi) \cos \theta+p \sin \theta], \\
B_{2}= & \frac{1}{4}\left(d^{2}+h^{2}\right) c+\frac{1}{2} \sqrt{d^{2}+h^{2}} \\
& \times\left[\left(r_{3} \sigma_{3}-a \tau_{n e} \sin \psi-a \sigma_{n e} \cos \psi\right)(\cos \theta \tan \varphi-\sin \theta)\right. \\
& \left.+B_{1}(\sin \theta \tan \varphi+\cos \theta)\right] .
\end{aligned}
$$




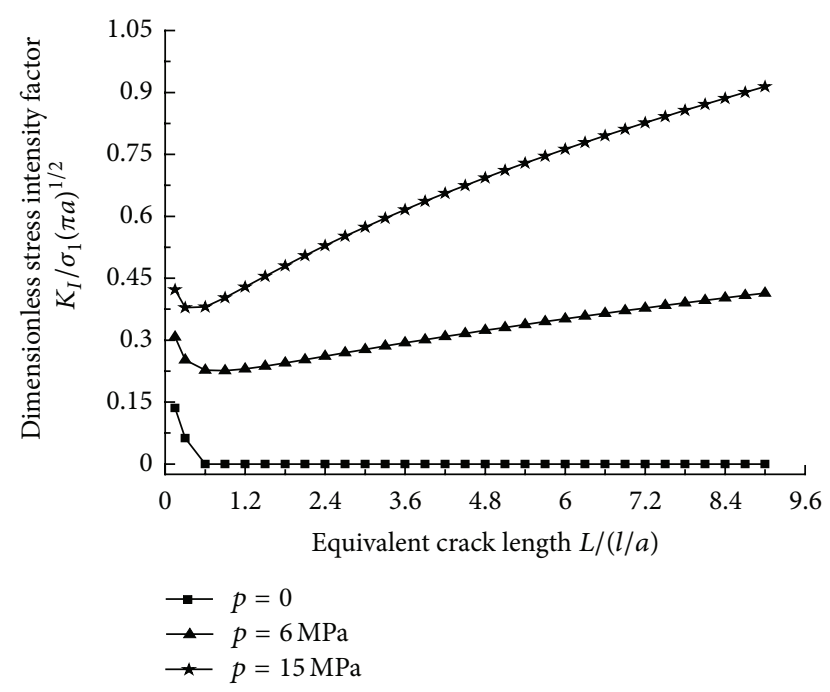

FIgURE 4: The relationship between intensity factor at the crack tip wing stress and crack propagation length.

Meanwhile, this paper gets the stress intensity factor at the crack tip when the wing reaches the critical length as follows:

$$
\begin{aligned}
K_{I}\left(l_{2 c}\right)= & K_{I}+K_{I}^{\prime}=3 \tau_{\text {eff }} \sqrt{\frac{a l_{t y}}{\pi}} \sin ^{-1}\left(\frac{1}{l_{t y}}\right) \sin (\theta) \cos (\theta) \\
& -\frac{1}{2}\left[\left(\sigma_{1}+\sigma_{3}\right)+\left(\sigma_{1}-\sigma_{3}\right) \cos ^{2}(\theta+\beta)\right] \sqrt{\pi l_{2 c}} \\
& +p \sqrt{\pi l_{2 c}}+\frac{a\left(\sigma_{1}-\sigma_{3}\right) \sin ^{2} \psi \sin \psi+2 p l_{2 c}}{2\left(l_{2 c}+a \cos \psi\right)-N_{A}^{-1 / 2}} \sqrt{\pi l_{2 c}} .
\end{aligned}
$$

\section{The Damage Evolution Mechanism of Multicrack Rock Masses}

The macroscopic mechanical effect of fractured rock would be reflected by the change of its flexibility, and then the damage tensor $D$ can be determined by the elastic flexibility tensor $C^{0}$ and the equivalent damage flexibility tensor $C^{d}$ [28]

$$
D=I-\frac{\left(C^{d}\right)^{-1}}{C^{0}}
$$

where $I$ is the fourth-order unit tensor and $D$ is a tensor of the fourth order for the 3D anisotropy mode of fractured rock.

In terms of the complete rock, the elastic flexibility tensor $C^{0}$ can be expressed as [29]

$$
C_{i j k l}^{0}=\frac{1+v_{0}}{E_{0}} \delta_{i k} \delta_{j l}-\frac{v_{0}}{E_{0}} \delta_{i j} \delta_{k l},
$$

where $E_{0}$ and $v_{0}$ represented the elastic modulus and Poisson's ratio of the rock, respectively.

The equivalent damage flexibility tensor $C^{d}$ can be drawn from Betti energy reciprocal theorem. Hence, based on selfconsistent method and strain energy equivalence in solid mechanics, the equivalent damage flexibility tensor $C_{i j k l}^{d}$ is acquired through calculating the equivalent elastic strain energy.

4.1. The Equivalent Damage Flexibility Tensor Based on Equivalent Elastic Strain Energy. The flexibility matrix of the crack in compression shear state is [30]

$$
\left[C^{0}\right]=\left[\begin{array}{ccc}
C_{11}^{0} & C_{11}^{0} & 0 \\
C_{21}^{0} & C_{22}^{0} & 0 \\
0 & 0 & C_{33}^{0}
\end{array}\right]
$$

Based on Betti's theorem, that is, Maxwell-Betti reciprocal work theorem, the work done by one set of forces through the displacements produced by another set of forces is equal to the work done by the latter set of forces through the displacements produced by the former set of forces.

(1) When $\sigma_{x}=\tau_{x y}=0, \sigma_{y} \neq 0$,

$$
\begin{gathered}
W_{12}=\left(2 b \sigma_{y}-2 a p\right)\left(C_{22} \sigma_{y}^{\prime} 2 d\right)=4\left(b \sigma_{y}-a p\right) \sigma^{\prime} d C_{22}, \\
W_{21}=\left(2 b \sigma_{y}^{\prime}\right)\left(\sigma_{y}-p\right) C_{22}^{0} 2 d+\Delta W_{c},
\end{gathered}
$$

where $\Delta W_{c}=\left(2 a \sigma_{y}^{\prime}\right)\left(\sigma_{y}-p\right) C_{n} / K_{n}$.

Then, we get

$$
W_{21}=4 \sigma_{y}^{\prime} d b C_{22}^{0}\left(\sigma_{y}-p\right)+\frac{2 a \sigma_{y}^{\prime}\left(\sigma_{y}-p\right) C_{n}}{K_{n}} .
$$

According to $W_{21}=W_{12}$, whilst, the crack size can be neglected compared to the size of the rock mass,

$$
C_{22}=(1-R)\left(C_{22}^{0}+\frac{a C_{n}}{2 K_{n} b d}\right),
$$

where $R=p / \sigma_{y}$.

(2) When $\sigma_{x}=\sigma_{y}=0, \tau_{x y} \neq 0$,

$$
\begin{gathered}
W_{12}=(\tau 2 d)\left(C_{33} \tau^{\prime} 2 b\right)=4 C_{33} \tau^{\prime} b d, \\
W_{21}=\left(\tau^{\prime} 2 d\right)\left(C_{33} \tau 2 b\right)+\Delta W_{c}=4 \tau C_{33} \tau^{\prime} b d+\Delta W_{c}, \\
\Delta W_{c}=\frac{\tau^{\prime} 2 a \tau C_{s}}{K_{s}} .
\end{gathered}
$$

Then, we obtain the following equation:

$$
W_{21}=4 \tau^{\prime} \tau d b C_{33}^{0}+\frac{2 a \tau^{\prime} \tau C_{s}}{K_{s}} .
$$

According to $W_{21}=W_{12}$, we get

$$
C_{33}=C_{33}^{0}+\frac{a C_{s}}{2 K_{s} b d} \text {. }
$$

Thus, the parameters of the equivalent damage flexibility matrix $\left[C^{d}\right]$ can be expressed as follows:

$$
\left[C^{d}\right]=\left[\begin{array}{ccc}
0 & 0 & 0 \\
0 & \frac{a C_{n}(1-R)}{2 K_{n} b d}-R C_{22}^{0} & 0 \\
0 & 0 & \frac{a C_{s}}{K_{s} 2 b d}
\end{array}\right]
$$


4.2. The Equivalent Damage Flexibility Tensor Based on Crack's Elastic Strain Energy. The strain energy of single crack is assumed as [29]

$$
U_{d}^{(i)}=2 \int_{0}^{a} G d \Gamma=2 \frac{1-v_{0}^{2}}{E_{0}} \int_{0}^{a}\left(K_{I}^{2}+K_{I I}^{2}\right) d a,
$$

where $\Gamma$ is the line length of cracks.

Integrating over the line length, the stress intensity factors of type $I$ or type $I I$ for the crack under seepage pressure are

$$
K_{I}^{(i)}=\sigma_{f}^{(i)} \sqrt{\pi a^{(i)}}, \quad K_{I I}^{(i)}=\tau_{q}^{(i)} \sqrt{\pi a^{(i)}},
$$

where $\sigma_{f}^{(i)}$ is the normal stress of the crack and $\tau_{q}^{(i)}$ is the tangential shear stress. Combining the former equation, then we get

$$
U_{d}^{(i)}=\frac{1-v_{0}^{2}}{E_{0}} \pi a^{(i) 2}\left[\sigma_{f}^{(i) 2}+\tau_{q}^{(i) 2}\right] .
$$

By assuming there are $n$ groups of cracks in the fractured rock mass, the strain energy of the fractured rock mass will be

$$
U_{d}=\sum_{i=1}^{n} U_{d}^{(i)}=\frac{1-v_{0}^{2}}{E_{0}} \pi \sum_{i=1}^{n} a^{(i) 2} \rho^{(i)}\left[\sigma_{f}^{(i) 2}+\tau_{q}^{(i) 2}\right] .
$$

Set the equation $H=\left(\left(1-v_{0}^{2}\right) / E_{0}\right) \pi, A^{(i)}=a^{(i) 2} \rho^{(i)}$, in which $\rho^{(i)}$ is the density of cracks, then

$$
U_{d}=H \sum_{i=1}^{n} A^{(i)}\left[\sigma_{f}^{(i) 2}+\tau_{q}^{(i) 2}\right]
$$

Rewrite (39) into the tensor expression

$$
U_{d}=\frac{1}{2} \sigma_{i j} C_{i j k l}^{d} \sigma_{k l}=H \sum_{i=1}^{n} A^{(i)}\left[\sigma_{f}^{(i)} \sigma_{f}^{(i)}+\tau_{q}^{(i)} \tau_{q}^{(i)}\right] .
$$

According to the hydrostatic pressure principle and Cauchy criterion, the remote field stress is denoted as $\sigma_{i j}$, and the stress matrix on the surface can be defined as [31]

$$
\left[\begin{array}{c}
T_{x}^{v} \\
T_{y}^{v}
\end{array}\right]=\left[\begin{array}{cc}
\sigma_{x x}-p & \sigma_{x y} \\
\sigma_{y x} & \sigma_{x x}-p
\end{array}\right]\left[\begin{array}{l}
v_{x} \\
v_{y}
\end{array}\right]
$$

Defining $n_{i} n_{i}=1$, authors rewrite the equation into the tensor expression

$$
T_{i}^{(i)}=\left(\sigma_{i j}^{(i)}-\delta_{i j} p\right) n_{j}^{(i)}=\sigma_{i j}^{(i)} n_{j}^{(i)}-p n_{i}^{(i)} .
$$

Considering the compression transferring coefficient $C_{n}$, the equivalent normal stress on the surface of the crack can be expressed as

$$
\begin{gathered}
\sigma_{f}^{(i)}=T_{i}^{(i)} n_{j}^{(i)}=\left(1-C_{n}^{(i)}\right) \sigma_{i j}^{(i)} n_{j}^{(i)} n_{i}^{(i)}-\beta^{(i)} p, \\
\left(\sigma_{f}^{(i)}\right)_{i}=\left(1-C_{n}\right) \sigma_{j k}^{(i)} n_{j}^{(i)} n_{k}^{(i)} n_{i}^{(i)}-\beta^{(i)} p n_{i}^{(i)} .
\end{gathered}
$$

Considering the shear transferring coefficient $C_{s}$ again, the shear stress on the crack surface can be expressed as

$$
\left(\tau_{f}^{(i)}\right)_{i}=T_{i}^{(i)}-\left(\sigma_{f}^{(i)}\right)_{i}=\left(1-C_{n}^{(i)}\right) \sigma_{j k}^{(i)} n_{j}^{(i)}\left(\delta_{k l}-n_{k}^{(i)} n_{i}^{(i)}\right) .
$$

Then, we get

$$
\begin{aligned}
\left(\sigma_{f}^{(i)}\right)_{i}\left(\sigma_{f}^{(i)}\right)_{i}= & \left(\left(1-C_{n}^{(i)}\right) \sigma_{j k}^{(i)} n_{j}^{(i)} n_{k}^{(i)} n_{i}^{(i)}-\beta^{(i)} p n_{i}^{(i)}\right) \\
& \times\left(\left(1-C_{n}^{(i)}\right) \sigma_{s t}^{(i)} n_{s}^{(i)} n_{t}^{(i)} n_{i}^{(i)}-\beta^{(i)} p n_{i}^{(i)}\right) .
\end{aligned}
$$

Considering the symmetry of $\sigma_{i j}$, the following equations can be deduced:

$$
\begin{aligned}
\left(\sigma_{f}^{(i)}\right)_{i}\left(\sigma_{f}^{(i)}\right)_{i}= & \left(1-C_{n}^{(i)}\right)^{2} \sigma_{j k}^{(i)} n_{j}^{(i)} n_{k}^{(i)} n_{s}^{(i)} n_{t}^{(i)} \sigma_{s t}^{(i)} \\
& -\left(1-C_{n}^{(i)}\right) \sigma_{j k}^{(i)} n_{j}^{(i)} n_{k}^{(i)} p \\
& -\left(1-C_{n}^{(i)}\right) \sigma_{s t}^{(i)} n_{s}^{(i)} n_{t}^{(i)} p+\beta^{(i)^{2}} p^{2}, \\
\left(\tau_{f}^{(i)}\right)_{i}\left(\tau_{f}^{(i)}\right)_{i}= & \left(1-C_{s}^{(i)}\right)^{2} \sigma_{j k}^{(i)} n_{j}^{(i)}\left(\delta_{k l}-n_{k}^{(i)} n_{i}^{(i)}\right) \sigma_{s t}^{(i)} n_{s}^{(i)} \\
& \times\left(\delta_{t i}-n_{i}^{(i)} n_{i}^{(i)}\right) \\
= & \left(1-C_{s}^{(i)}\right)^{2} \sigma_{j k}^{(i)} \\
& \times\left(\delta_{k l} n_{j}^{(i)} n_{s}^{(i)}-n_{j}^{(i)} n_{k}^{(i)} n_{s}^{(i)} n_{t}^{(i)}\right) \sigma_{s t}^{(i)} .
\end{aligned}
$$

Supposing the proportion coefficient $R=p / \bar{\sigma}, \bar{\sigma}$ is the average stress, $\bar{\sigma}=(1 / 2) \sigma_{i i}, \sigma_{i i}$ is the first invariant stress. Then, the seepage pressure can be transformed to

$$
\begin{aligned}
p & =p \frac{\sigma_{s s}}{\sigma_{s s}}=\sigma_{s t} \delta_{s t} \frac{p}{2 \bar{\sigma}}=\frac{1}{2} \sigma_{s t} \delta_{s t} R, \\
p^{2} & =p^{2} \frac{\sigma_{k k}}{\sigma_{k k}} \frac{\sigma_{s s}}{\sigma_{s s}}=\sigma_{k j} \delta_{k j} \sigma_{s t} \delta_{t s} \frac{p}{2 \bar{\sigma}} \frac{p}{2 \bar{\sigma}} \\
& =\frac{1}{4} \sigma_{k j} \delta_{k j} \sigma_{s t} \delta_{t s} R^{2} .
\end{aligned}
$$

Then, we get

$$
\begin{aligned}
\left(\sigma_{f}^{(i)}\right)_{i}\left(\sigma_{f}^{(i)}\right)_{i} & \\
= & \left(1-C_{n}^{(i)}\right)^{2} \sigma_{j k}^{(i)} n_{j}^{(i)} n_{k}^{(i)} n_{s}^{(i)} n_{t}^{(i)} \sigma_{s t}^{(i)} \\
& -\frac{1}{2}\left(1-C_{n}^{(i)}\right) R \sigma_{j k}^{(i)} \\
& \times\left(n_{j}^{(i)} n_{k}^{(i)} \sigma_{s t}^{(i)}+\delta_{j k} n_{s}^{(i)} n_{t}^{(i)}\right) \\
& +\frac{1}{4}\left(\beta^{(i)} R\right)^{2} \sigma_{j k}^{(i)} \sigma_{s t}^{(i)} \sigma_{t s},
\end{aligned}
$$




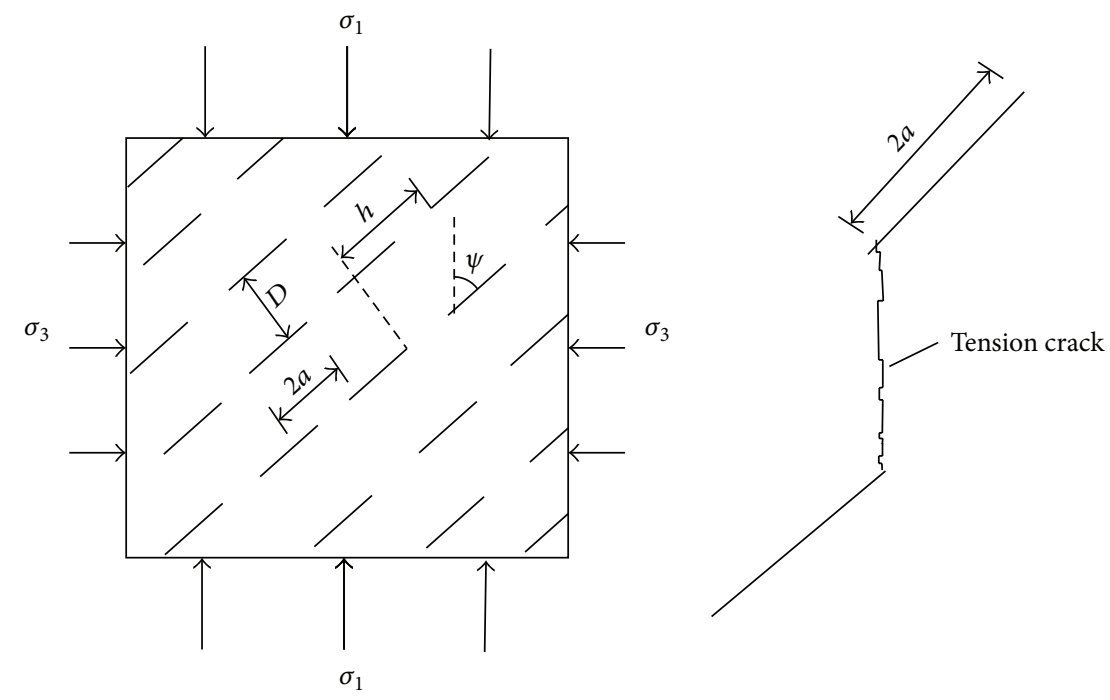

FIGURE 5: Failure characteristic of crag bridge shearing.

$$
\begin{aligned}
U_{d}=\frac{1}{2} \sigma_{j k} C_{j k s t}^{d} \sigma_{s i} & \\
=H \sum_{i=1}^{n} A^{(i)} \sigma_{j k}^{(i)}[ & \left(1-C_{n}^{(i)}\right)^{2} n_{j}^{(i)} n_{k}^{(i)} n_{s}^{(i)} n_{t}^{(i)} \\
& -\frac{1}{2}\left(1-C_{n}^{(i)}\right) \beta^{(i)} R \sigma_{j k}^{(i)} \\
& \times\left(n_{j}^{(i)} n_{k}^{(i)} \sigma_{s t}^{(i)}+\delta_{j k} n_{s}^{(i)} n_{t}^{(i)}\right) \\
& +\frac{1}{4}\left(R \beta^{(i)}\right)^{2} \sigma_{j k}^{(i)} \sigma_{s t}^{(i)} \sigma_{t s}+\left(1-C_{s}^{(i)}\right)^{2} \\
& \left.\times\left(\delta_{k t} n_{j}^{(i)} n_{s}^{(i)}-n_{j}^{(i)} n_{k}^{(i)} n_{s}^{(i)} n_{t}^{(i)}\right)\right] \sigma_{s t}^{(i)}
\end{aligned}
$$

Finally, it is clear to conclude the additional flexibility tensor of fractured rock mass under seepage pressure as follows:

$$
\begin{aligned}
C_{i j k l}^{d}= & \left(1-C_{n}^{(i)}\right)^{2} n_{j}^{(i)} n_{k}^{(i)} n_{s}^{(i)} n_{t}^{(i)} \\
& -\frac{1}{2}\left(1-C_{n}^{(i)}\right) \beta^{(i)} R \sigma_{j k}^{(i)}\left(n_{j}^{(i)} n_{k}^{(i)} \sigma_{s t}^{(i)}+\delta_{j k} n_{s}^{(i)} n_{t}^{(i)}\right) \\
& +\frac{1}{4}\left(R \beta^{(i)}\right)^{2} \sigma_{j k}^{(i)} \sigma_{s t}^{(i)} \sigma_{t s} \\
& +\left(1-C_{s}^{(i)}\right)^{2}\left(\delta_{k t} n_{j}^{(i)} n_{s}^{(i)}-n_{j}^{(i)} n_{k}^{(i)} n_{s}^{(i)} n_{t}^{(i)}\right) .
\end{aligned}
$$

4.3. The Fracture Damage Evolution Equation. The additional elastic strain energy density $u_{k z}^{i}$ produced by the wing crack is [32]

$$
u_{k z}^{(i)}=\frac{4}{E_{0}} \rho_{v}^{(i)} a^{(i) 2}\left(\frac{5}{2} \sigma_{\mathrm{eff}}^{(i)} L^{(i)}+\frac{2}{\sqrt{3}} \tau_{\mathrm{eff}}^{(i)}\right)^{2},
$$

where $L^{(i)}$ is the equivalent length for the crack.
Assuming there are $n$ groups of cracks in the fractured rock mass, the additional elastic strain energy density of the fractured $\operatorname{rock} U_{k z}$ is

$$
U_{k z}=\sum_{i=1}^{n} u_{k z}^{(i)}=\frac{1}{2} \sigma_{i j} C_{i j k l}^{k z} \sigma_{k l} .
$$

Crack extension reduces the stiffness of rock masses and increases its flexibility. Through the derivative of $U_{k z}$ with respect to the stress tensor, we can get the additional flexibility tensor of fractured rock masses in the damage evolution process

$$
\frac{\partial U_{k z}}{\partial \sigma_{i j}}=C_{i j k l}^{k z} \sigma_{k l}
$$

At the same time, by calculating the partial derivative of $L^{(i)}, \sigma_{\text {eff }}^{(i)}$, and $\tau_{\text {eff }}^{(i)}$ with respect to $\sigma_{i j}$, respectively, and considering the symmetry of $C_{i j k l}^{k z}$, we can get the following results:

$$
\begin{aligned}
\frac{\partial U_{k z}}{\partial \sigma_{i j}}=\frac{1}{E_{0}} \sum_{i=1}^{n}\left\{a^{(i) 2} \rho_{v}^{(i)}[\right. & M_{1}^{(i)} n_{j}^{(i)} n_{k}^{(i)} n_{k}^{(i)} n_{t}^{(i)}-M_{2}^{(i)} \\
& \times\left(n_{j}^{(i)} n_{k}^{(i)} \delta_{k j}+\delta_{k i} n_{j}^{(i)} n_{t}^{(i)}\right. \\
& \left.+n_{j}^{(i)} n_{k}^{(i)} \delta_{i j}+\delta_{i t} n_{j}^{(i)} n_{k}^{(i)}\right) \\
& \left.\left.-\frac{M_{3}^{(i)}}{3} \beta R \delta_{i j} \delta_{k l}\right]\right\} \sigma_{k l},
\end{aligned}
$$




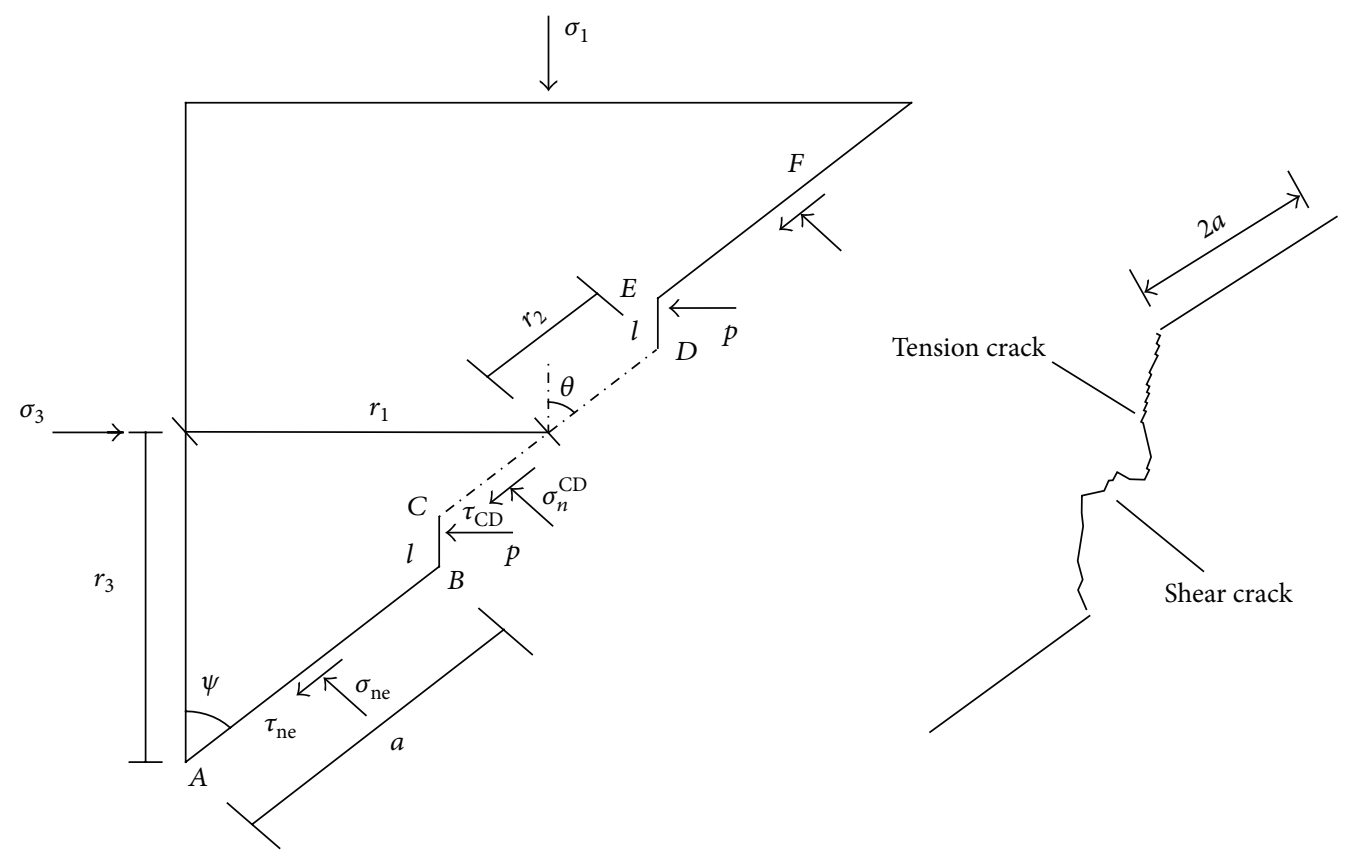

FIGURE 6: Failure characteristic of crag bridge shearing.

where

$$
\begin{aligned}
& M_{1}^{(i)}=\left(20 \sigma_{\mathrm{eff}}^{(i)} L^{(i)}+\frac{16}{\sqrt{3}} \tau_{\mathrm{eff}}^{(i)}\right) \\
& \times\left[\frac{1}{\sigma_{n}^{(i)}}\left(\frac{5}{2} L^{(i)}+\frac{2}{\sqrt{3}} f\right)\right. \\
& \left.-\frac{1}{\tau_{n}^{(i)}}\left(\frac{5}{2} \cot \theta^{(i)} L^{(i)}+\frac{2}{\sqrt{3}} f\right)+\frac{5}{2} \sigma_{\mathrm{eff}}^{(i)} N_{1}^{(i)}\right], \\
& M_{2}^{(i)}=\left(5 \sigma_{\mathrm{eff}}^{(i)} L^{(i)}+\frac{4}{\sqrt{3}} \tau_{\mathrm{eff}}^{(i)}\right) \\
& \times\left[\frac{1}{\tau_{n}^{(i)}}\left(\frac{5}{2} \cot \theta^{(i)} L^{(i)}+\frac{2}{\sqrt{3}} f\right)+\frac{5}{2} \sigma_{\mathrm{eff}}^{(i)} N_{2}^{(i)}\right], \\
& M_{3}^{(i)}=\left(20 \sigma_{\text {eff }}^{(i)} L^{(i)}+\frac{16}{\sqrt{3}} \tau_{\text {eff }}^{(i)}\right) \\
& \times\left[\frac{2}{\sqrt{3}} f+\frac{5}{2}\left(\sigma_{\mathrm{eff}}^{(i)} N_{3}^{(i)}+L^{(i)}\right)\right], \\
& N_{1}^{(i)}=\sqrt{L^{(i)}}\left[-4 a^{(i)} \cos \theta^{(i)} \sigma_{\text {eff }}^{(i) 2}\left(f \tau_{n}^{(i)}-\sigma_{n}^{(i)}\right)\right. \\
& -\left(K_{I C}^{(i) 2}-4 a^{(i)} \cos \theta^{(i)} \sigma_{\text {eff }}^{(i)}\right. \\
& \left.-2 \sqrt{\pi a^{(i)}} A^{(i)} K_{I C}^{(i)} \sigma_{\text {eff }}^{(i)}\right) \\
& \left.\times\left(\tau_{n}^{(i)}-\sigma_{n}^{(i)} \cot \theta^{(i)}\right)\right] \\
& \times\left(2 \pi a^{(i)} A^{(i)} \sigma_{\mathrm{eff}}^{(i)} \sigma_{n}^{(i)} \tau_{n}^{(i)}\right)^{-1}, \\
& N_{2}^{(i)}=\sqrt{L^{(i)}}\left[-4 a^{(i)} \cos \theta^{(i)} \sigma_{\text {eff }}^{(i) 2}\right. \\
& -\left(K_{I C}^{(i)^{2}}-4 a^{(i)} \cos \theta^{(i)} \sigma_{\mathrm{eff}}^{(i)} \tau_{\mathrm{eff}}^{(i)}\right. \\
& \left.\left.-2 \sqrt{\pi a^{(i)}} A^{(i)} K_{I C}^{(i)} \sigma_{\text {eff }}^{(i)}\right) \cot \theta^{(i)}\right] \\
& \times\left(2 \pi a^{(i)} A^{(i)} \sigma_{\mathrm{eff}}^{(i)} \sigma_{n}^{(i)} \tau_{n}^{(i)}\right)^{-1} \text {, }
\end{aligned}
$$

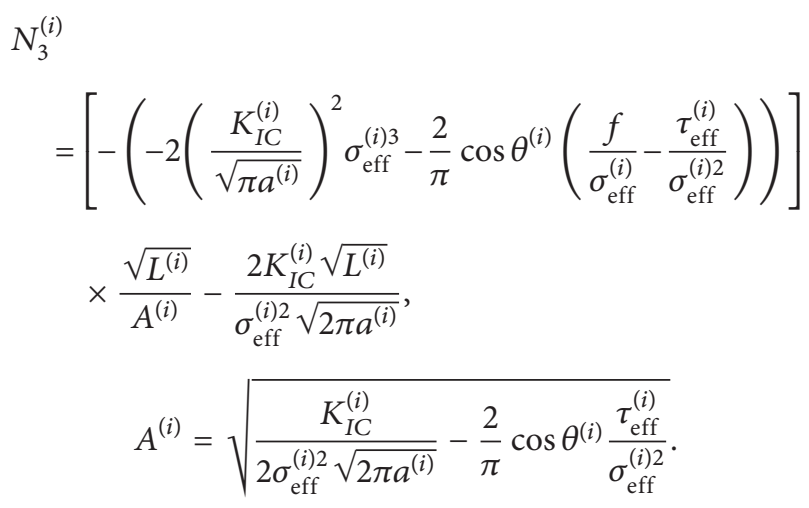

Then, we can get the flexibility tensor $C_{i j k l}^{k z}$ due to the damage evolution of fractured rock masses as follows:

$$
\begin{aligned}
& C_{i j k l}^{k z}=\frac{1}{E_{0}} \sum_{i=1}^{n}\left\{a ^ { ( i ) 2 } \rho _ { v } ^ { ( i ) } \left[M_{1}^{(i)} n_{j}^{(i)} n_{k}^{(i)} n_{k}^{(i)} n_{t}^{(i)}-M_{2}^{(i)}\right.\right. \\
& \times\left(n_{j}^{(i)} n_{k}^{(i)} \delta_{k j}+\delta_{k i} n_{j}^{(i)} n_{t}^{(i)}\right. \\
& \left.+n_{j}^{(i)} n_{k}^{(i)} \delta_{i j}+\delta_{i t} n_{j}^{(i)} n_{k}^{(i)}\right) \\
& \left.\left.-\frac{M_{3}^{(i)}}{3} \beta R \delta_{i j} \delta_{k l}\right]\right\} \text {. }
\end{aligned}
$$

4.4. The Constitutive Equation of the Multicrack Rock Mass. To sum up, combining the initial damage and damage 
evolution tensor, we can get the flexibility tensor of the fractured rock mass under seepage pressureas follows:

$$
C_{i j k l}=C_{i j k l}^{0}+C_{i j k l}^{d}+C_{i j k l}^{k z}
$$

where $C_{i j k l}^{0}$ is the elastic flexibility tensor of the complete rock, $C_{i j k l}^{d}$ is the initial equivalent damage flexibility tensor of the fractured rock mass under seepage pressure, and $C_{i j k l}^{k z}$ is the additional damage flexibility tensor with crack propagation of the fractured rock mass under seepage pressure.

According to generalized Hooke's law [33]:

$$
\begin{gathered}
\varepsilon_{i j}=C_{i j k l} \sigma_{k l}, \\
\sigma_{i j}=E_{i j k l} \varepsilon_{k l}=\left(C_{i j k l}\right)^{-1} \varepsilon_{k l},
\end{gathered}
$$

and this paper sets up the constitutive relation of the multicrack rock mass under seepage pressure.

\section{Conclusions}

After discussing the damage and fracture evolution mechanism of the multicrack rock mass under compression-shear stress and seepage pressure, the following main conclusions are drawn.

(1) Through proposing the fractured damage model of the multicrack rock mass under the combined action of compression-shear stress and seepage pressure, this paper discusses the law of crack initiation and the evolution law of stress intensity factor at the tip of a wing crack. The interaction of multiple cracks makes the stress intensity factor at the crack tip larger than that of a single wing crack. Regarding the seepage pressure, the existence of that reinforces the wing crack's propagation. Moreover, the high seepage pressure converts wing crack growth from stable form to unstable form.

(2) The wing crack initiation from microcracks to the completely damage of the rock mass is a process of evolution and accumulation of the rock mass damage, as well as a process of the fracture of the connection between cracks. Based on the criterion and mechanism for crack initiation and propagation, this paper puts forward the mechanical model for different fracture transfixion failure modes of the crag bridge under the combined action of seepage pressure and compression-shear stress.

(3) According to the strain energy equivalent principle, this paper applies Betti's reciprocal work theorem of the fractured rock mass to study the flexibility tensor of the rock mass's initial damage and its damage evolution and deduces the damage constitutive equations for the elastic-plastic fracture and damage evolution. The theory provides a reliable theoretical principle for quantitative research of the fractured rock mass failure under seepage pressure.

\section{Acknowledgments}

This paper gets its funding from Projects (51174228, 51274249, 41002090) supported by the National Natural Science Foundation of China; Project supported by the Hunan Provincial Innovation Foundation for Postgraduate; Project (20120162120014) supported by the Specialized Research Fund for the Doctoral Program of Higher Education of China; Project (12KF01) supported by the Open Projects of State Key Laboratory of Coal Resources and Safe Mining, CUMT. The authors wish to acknowledge these supports.

\section{References}

[1] V. Kuksenko, N. Tomilin, and A. Chmel, "The rock fracture experiment with a drive control: a spatial aspect," Tectonophysics, vol. 431, no. 1-4, pp. 123-129, 2007.

[2] S. Marfia and E. Sacco, "A fracture evolution procedure for cohesive materials," International Journal of Fracture, vol. 110, no. 3, pp. 241-261, 2001.

[3] L. N. Lens, E. Bittencourt, and V. M. R. d'Avila, "Constitutive models for cohesive zones in mixed-mode fracture of plain concrete," Engineering Fracture Mechanics, vol. 76, no. 14, pp. 2281-2297, 2009.

[4] M. K. Rahman, Y. A. Suarez, Z. Chen, and S. S. Rahman, "Unsuccessful hydraulic fracturing cases in Australia: investigation into causes of failures and their remedies," Journal of Petroleum Science and Engineering, vol. 57, no. 1-2, pp. 70-81, 2007.

[5] R. P. Orense, S. Shimoma, K. Maeda, and I. Towhata, "Instrumented model slope failure due to water seepage," Journal of Natural Disaster Science, vol. 26, pp. 15-26, 2004.

[6] M. M. Hossain and M. K. Rahman, "Numerical simulation of complex fracture growth during tight reservoir stimulation by hydraulic fracturing," Journal of Petroleum Science and Engineering, vol. 60, no. 2, pp. 86-104, 2008.

[7] D. Hoxha, M. Lespinasse, J. Sausse, and F. Homand, "A microstructural study of natural and experimentally induced cracks in a granodiorite," Tectonophysics, vol. 395, no. 1-2, pp. 99-112, 2005.

[8] M. Sagong and A. Bobet, "Coalescence of multiple flaws in a rock-model material in uniaxial compression," International Journal of Rock Mechanics and Mining Sciences, vol. 39, no. 2, pp. 229-241, 2002.

[9] R. H. C. Wong, K. T. Chau, C. A. Tang, and P. Lin, "Analysis of crack coalescence in rock-like materials containing three flaws-part I: experimental approach," International Journal of Rock Mechanics and Mining Sciences, vol. 38, no. 7, pp. 909-924, 2001.

[10] S. Y. Wang, S. W. Sloan, D. C. Sheng, and C. A. Tang, "Numerical analysis of the failure process around a circular opening in rock," Computers and Geotechnics, vol. 39, pp. 8-16, 2012.

[11] O. Mutlu and A. Bobet, "Slip initiation on frictional fractures," Engineering Fracture Mechanics, vol. 72, no. 5, pp. 729-747, 2005.

[12] Y. Nara and K. Kaneko, "Study of subcritical crack growth in andesite using the Double Torsion test," International Journal of Rock Mechanics and Mining Sciences, vol. 42, no. 4, pp. 521-530, 2005.

[13] M. Haggerty, Q. Lin, and J. F. Labuz, "Observing deformation and fracture of rock with speckle patterns," Rock Mechanics and Rock Engineering, vol. 43, pp. 417-426, 2010. 
[14] C. Dascalu, B. François, and O. Keita, "A two-scale model for subcritical damage propagation," International Journal of Solids and Structures, vol. 47, no. 3-4, pp. 493-502, 2010.

[15] S. Misra, "Deformation localization at the tips of shear fractures: an analytical approach," Tectonophysics, vol. 503, no. 1-2, pp. 182-187, 2011.

[16] M. F. Ashby and S. D. Hallam, "The failure of brittle solids containing small cracks under compressive stress states," Acta Metallurgica, vol. 34, no. 3, pp. 497-510, 1986.

[17] C. Fairhurst and N. G. W. Cood, "The phenomenon of rock splitting parallel to the direction of maximum compression in the neighbourhood of a surface," in Proceedings of the Congress of the International Society of Rock Mechanics, L. Muller, Ed., pp. 687-692, Balkema, Rotterdam, The Netherlands, 1966.

[18] H. P. Yuan, P. Cao, and W. Z. Xu, "Mechanism study on subcritical crack growth of flabby and intricate ore rock," Transactions of Nonferrous Metals Society of China, vol. 16, no. 3, pp. 723-727, 2006.

[19] E. Sahouryeh, A. V. Dyskin, and L. N. Germanovich, "Crack growth under biaxial compression," Engineering Fracture Mechanics, vol. 69, no. 18, pp. 2187-2198, 2002.

[20] S.-H. Zheng, Research on Coupling Theory Between Seepage and Damage of Fractured Rock Mass and Its Application to Engineering, Wuhan Institute of Rock and Soil Mechanics Chinese Academy of Scinces, Wuhan, China, 2000.

[21] T. Liu, P. Cao, and H. Lin, "Analytical solutions for the seepage induced fracture failure propagation in rock mass," Journal of Disaster Advances, vol. 3, supplement 1, pp. 307-314, 2013.

[22] L. N. Y. Wong and H. H. Einstein, "Using high speed video imaging in the study of cracking processes in rock," Geotechnical Testing Journal, vol. 32, no. 2, pp. 164-180, 2009.

[23] W. Zhu and Q. Zhang, "Brittle elastic fracture damage constitutive model of jointed rockmass and its application to engineering," Chinese Journal of Rock Mechanics and Engineering, vol. 18, no. 3, pp. 245-249, 1999.

[24] K. Y. Lam and S. P. Phua, "Multiple crack interaction and its effect on stress intensity factor," Engineering Fracture Mechanics, vol. 40, no. 3, pp. 585-592, 1991.

[25] M. Kachanov, "On the problems of crack interactions and crack coalescence," International Journal of Fracture, vol. 120, no. 3, pp. 537-543, 2003.

[26] H. Qing and W. Yang, "Characterization of strongly interacted multiple cracks in an infinite plate," Theoretical and Applied Fracture Mechanics, vol. 46, no. 3, pp. 209-216, 2006.

[27] A. P. S. Selvadurai and Q. Yu, "Mechanics of a discontinuity in a geomaterial," Computers and Geotechnics, vol. 32, no. 2, pp. 92106, 2005

[28] X. P. Yuan, H. Y. Liu, and Z. Q. Wang, "An interacting crackmechanics based model for elastoplastic damage model of rocklike materials under compression," International Journal of Rock Mechanics and Mining Sciences, vol. 58, pp. 92-102, 2013.

[29] B. Franois and C. Dascalu, "A two-scale time-dependent damage model based on non-planar growth of micro-cracks," Journal of the Mechanics and Physics of Solids, vol. 58, no. 11, pp. 1928-1946, 2010.

[30] V. Palchik and Y. H. Hatzor, "Crack damage stress as a composite function of porosity and elastic matrix stiffness in dolomites and limestones," Engineering Geology, vol. 63, no. 3-4, pp. 233-245, 2002.

[31] G. Alfano, S. Marfia, and E. Sacco, "A cohesive damagefriction interface model accounting for water pressure on crack propagation," Computer Methods in Applied Mechanics and Engineering, vol. 196, no. 1-3, pp. 192-209, 2006.

[32] V. Monchiet, C. Gruescu, O. Cazacu, and D. Kondo, "A micromechanical approach of crack-induced damage in orthotropic media: application to a brittle matrix composite," Engineering Fracture Mechanics, vol. 83, pp. 40-53, 2012.

[33] A. Golshani, Y. Okui, M. Oda, and T. Takemura, "A micromechanical model for brittle failure of rock and its relation to crack growth observed in triaxial compression tests of granite," Mechanics of Materials, vol. 38, no. 4, pp. 287-303, 2006. 


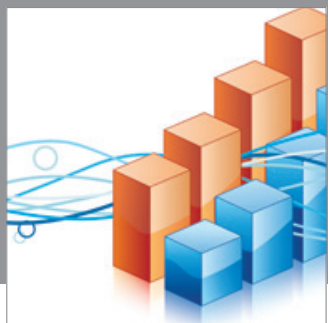

Advances in

Operations Research

mansans

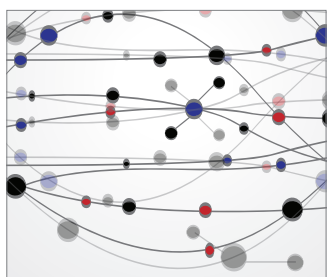

The Scientific World Journal
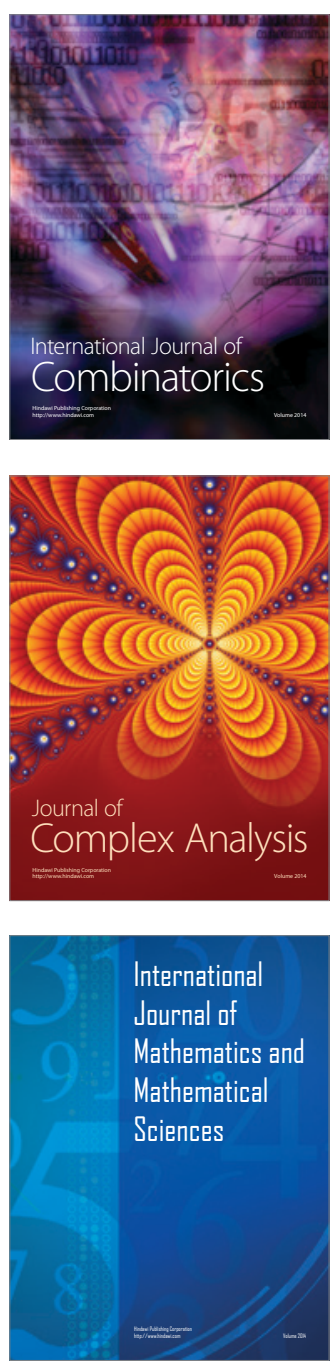
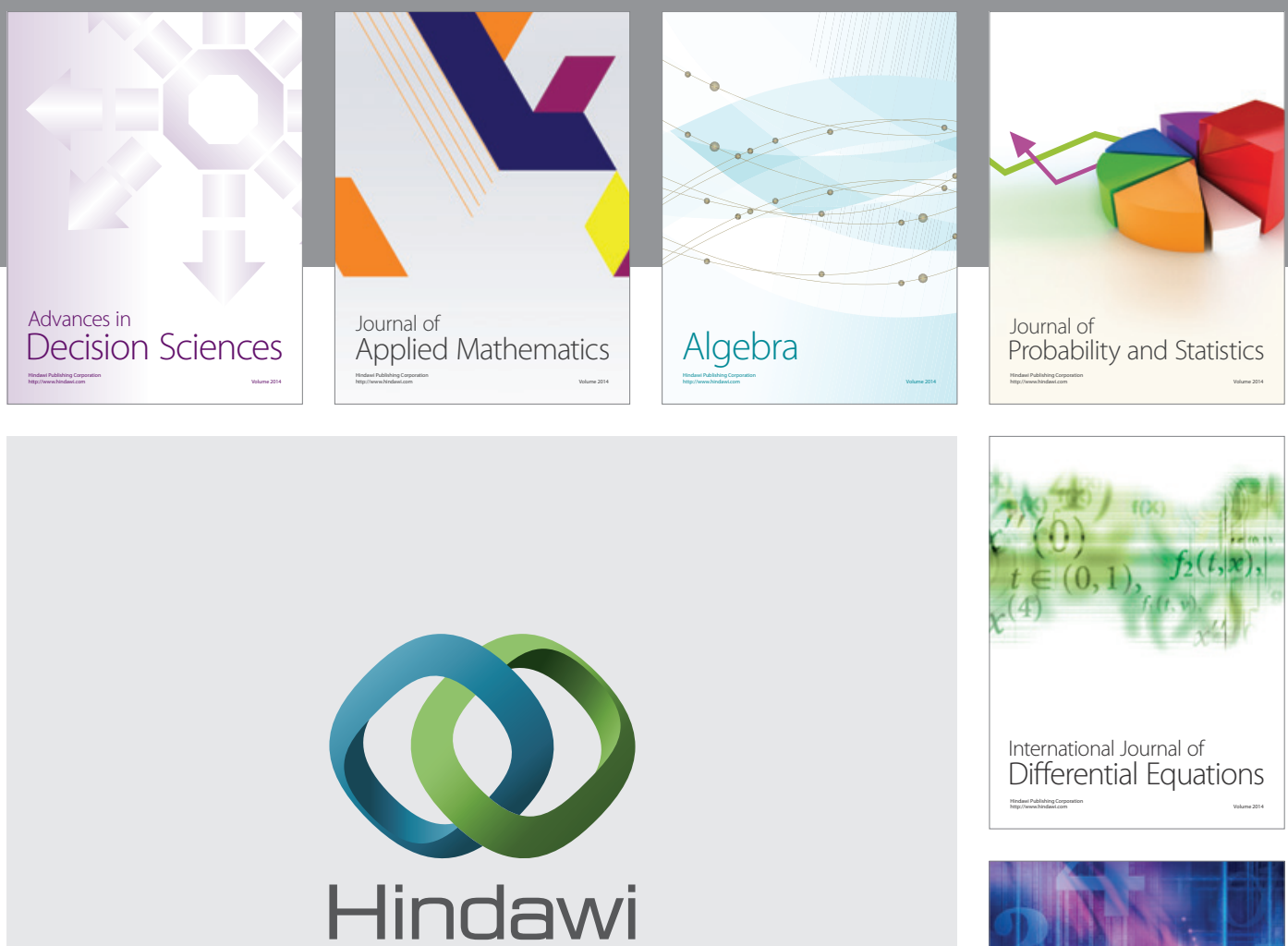

Submit your manuscripts at http://www.hindawi.com
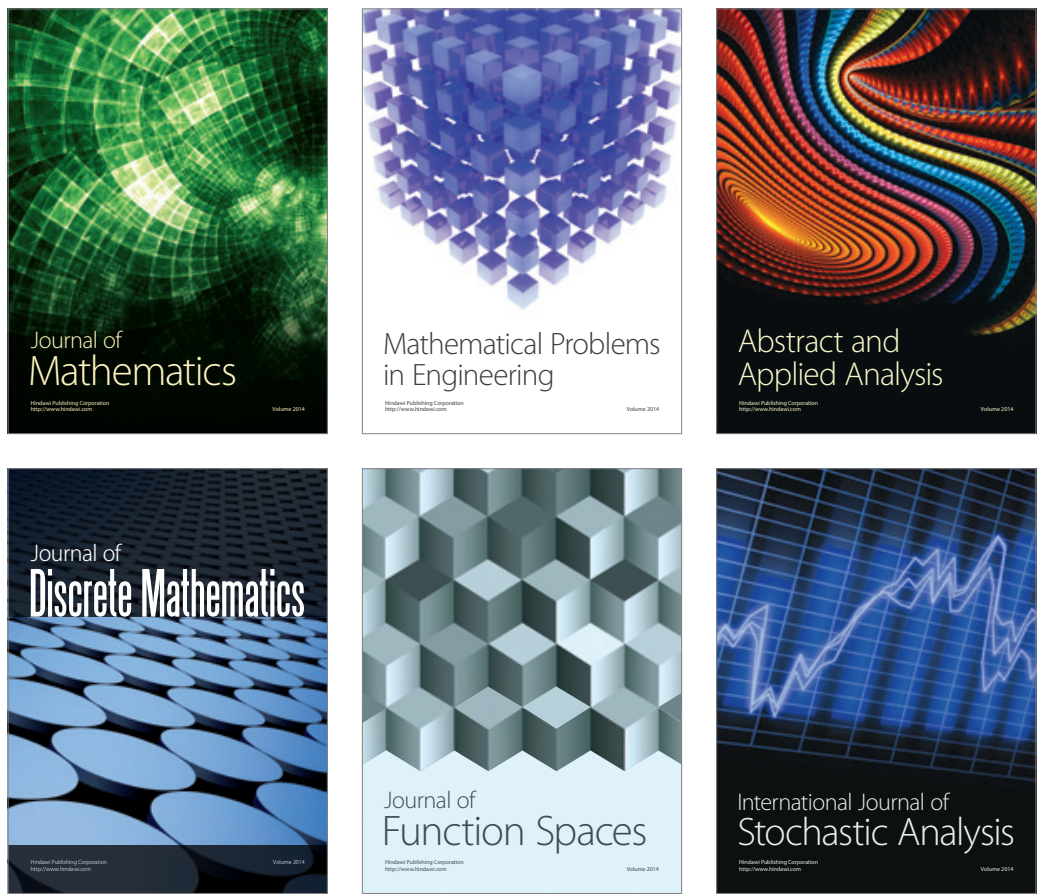

Journal of

Function Spaces

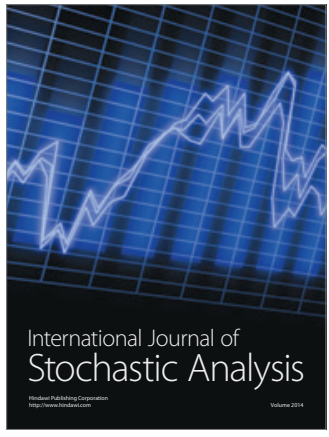

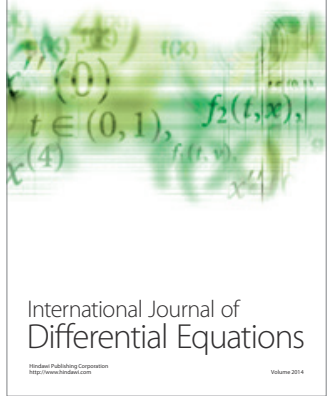
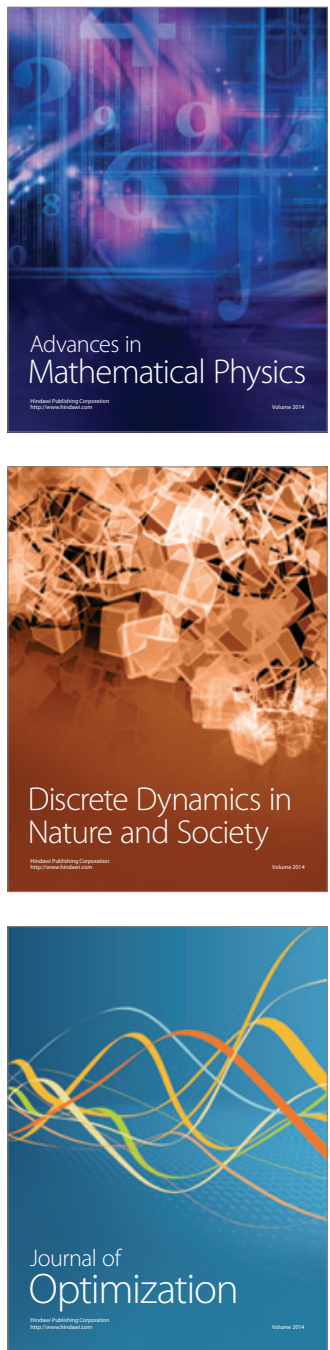